\title{
PENGARUH DIFERENSIASI, PROMOSI DAN POSITIONING TERHADAP KEPUTUSAN PEMBELIAN PADA LAPTOP ASUS
}

\author{
Nofritar \\ Universitas Putra Indonesia YPTK Padang, Indonesia \\ Nofritar999@gmail.com
}

\begin{abstract}
This study aims to determine how much Influence of Differentiation, Promotion and Positioning Against Buying Decision Brands Asus Laptop, data collection method is to circulate a questionnaire with a sample of 100. The analytical method used is multiple regression regression analysis. The results obtained are: (a) Differentiation has an influence on purchasing decisions by 0.149. Then the differentiation has a positive and significant influence, with Ho rejected and Ha accepted. (b) Promotion of 0.405 has an influence on purchasing decisions. Then promotion has a positive and significant influence, with Ho rejected and Ha accepted. (c) Positioning has the effect of 0,032 on purchase decisions. Then positioning has a positive and significant influence, with Ho rejected and Ha accepted. (d) differentiation, promotion and amounted to 19.520 psitioning have influence on purchasing decisions. Then the value

of $(R)^{2}$ of 0,718 which means differentiation, promotion and positioning has a positive and significant relationship, so Ho rejected and Ha accepted. Finally, the author suggests Laptop Asus is expected to increase differentiation by observing characteristic, value, image and price in order to give satisfaction to the customers so that they can be enjoyed by the wider community, can improve product promotion Asus laptop that is known by many people and can improve the positioning on the product Asus laptops are comprised of high tech and high touch positioning positioning.
\end{abstract}

Keywords: Purchase Decision, Differentiation, Promotions, Positioning

\section{PENDAHULUAN}

Perkembangan teknologi informasi yang semakin pesat membawa perubahan yang cukup besar terhadap perubahan perilaku dan lingkungan, baik dalam dunia pendidikan, perusahaan, maupun lingkungan masyarakat secara umum.Perubahan-perubahan yang mengarah pada efektifitas dan efesiensi kerja sangat mewarnai perubahan tersebut. Sehingga terciptanya persaingan dalam memasarkan produk dengan tujuan menciptakan pelanggan. Sebuah perusahaan perlu membangun strategi pemasaran yang baik. Strategi yang harus dilakukan dalam upaya mencapai target pemasaran dimulai dari dalam perusahaan, khususnya produk yang diciptakan oleh perusahaan. Strategi yang perlu dilakukan oleh sebuah perusahaan dalam pengembangan produk seperti diferensiasi produk yang merupakan strategi yang harus dilakukan oleh sebuah perusahaan.

Untuk setiap produk yang telah diciptakan oleh sebuah perusahaan dengan segala keunggulannya tersebut kepada konsumen, maka perusahaan perlu menerapkan strategi promosi yang baik, dimana tujuan utama dari promosi adalah memperkenalkan (menginformasikan), membujuk, serta mengingatkan pelanggan tentang produk sebuah perusahaan dan. Perusahaan di dalam upaya memasarkan produknya selain dengan promosi masih perlu strategi pemasaran lain yang baik dan tepat. Semua strategi pemasaran dibangun diatas STP yaitu Segmenting (segmentasi), Targeting(pembidikan), dan Positioning (penetapan posisi). Pengertian penempatan posisi (positioning) adalah tindakan merancang tawaran dan citra perusahaan sehingga menempati posisi yang khas diantara pesaing di dalam benak pelanggan sasarannya.

Seiring meningkatnya penggunaan perangkat elektronik seperti laptop,banyaknya jumlah mahasiswa atau pelajaryang merupakan pangsa pasar yang tinggi terhadap pengguna laptop. Dengan tingginya tingkat persaingan,maka perusahaan-perusahaan banyak mengeluarkan merek laptop yang beredar dipasaran.Sehingga dapat menciptakan persaingan yang ketat bagi pelaku bisnis dalam upaya 
memenuhi kebutuhan konsumen dalam keputusan pembelian. Sebagai salah satu laptop merek Asus telah banyak di pasarkan, namun peminat laptop merek Asus masih sedikit sehingga menyebabkan keputusan pembelian rendah, padahal harga yang di tawarkan Asus lebih rendah. Keputusan pembelian juga di pengaruhi oleh promosi, untuk promosi laptop Asus masih kurang di bandingkan dengan merek lainnya. Penulis merasa promosi yang dilakukan oleh oleh perusahaan masih sangat kurang dibandingkan dengan merek-merek laptop lainnya

Tabel 1.1Data Penjualan Laptop Pada

Tahun 2012-2016

\begin{tabular}{|c|cc|cc|c|c|}
\hline \multirow{2}{*}{ MEREK } & \multicolumn{5}{|c|}{ TAHUN } & \multirow{2}{*}{ \% MARKET } \\
\cline { 2 - 5 } & $\mathbf{2 0 1 2}$ & $\mathbf{2 0 1 3}$ & $\mathbf{2 0 1 4}$ & $\mathbf{2 0 1 5}$ & $\mathbf{2 0 1 6}$ & SHARE \\
Lenovo & 894.691 & 1.209 .481 & 2.197 .399 & 2.860 .980 & 2.916 .234 & $24 \%$ \\
Acer & 3.326 .038 & 3.135 .731 & 3.838 .450 & 3.900 .892 & 3.795 .998 & $10,4 \%$ \\
Apel & 545.648 & 507.168 & 1.626 .626 & 1.735 .178 & 2.617 .759 & $15,8 \%$ \\
Asus & 598.019 & 539.641 & 702.182 & 1.301 .356 & 1.792 .149 & $8,7 \%$ \\
Toshiba & 3.049 .416 & 3.907 .255 & 3.726 .060 & 3.117 .882 & 3.472 .575 & $41,1 \%$ \\
\hline Total & 8.413 .812 & 9.299 .276 & 12.090 .717 & 12.916 .288 & 14.594 .715 & $100 \%$ \\
\hline \multicolumn{3}{|c|}{ Sumber: hitp://swacoid } \\
\hline
\end{tabular}

Berdasarkan pada data penjualan laptop pada tahun 2011-2015, market share laptop merek asus yaitu $8,7 \%$. Berarti laptop merek asus berada di tangan pengikut pasar, laptop merek acer 10,4\% sebagai pengikut pasar, merek toshiba $41,1 \%$ sebagai penantang pasar, lenovo sebesar $24 \%$ sebagai penantang pasar, dan merek apel 15,8 \% sebagai pengikut pasar. Jadi market share yang paling rendah berada pada merek asus yaitu $8,7 \%$ sebagai pengikut pasar.

Fenomena yang terdapat pada laptop merek asus ini adalah peminatnya terlalu sedikit yang mengakibatkan keputusan pembelian pada laptop merek asus rendah.Penyebabnya adalah diferensiasi laptop asus masih rendah dibandingkan dengan laptop merek lain. Dengan diferensiasi masih rendah sehingga menimbulkan banyaknya fenomena-fenomena yang terdapat dalam laptop asus.

Promosi laptop asus sendiri masih sangat kurang di banding laptop merek lain, hal ini terbukti dari sedikitnya iklan-iklan terhadap laptop merek asus. Sehingga posotioning laptop merek asus pada pangsa pasar sangat kurang yang menyebabkan keputusan pembelian pada merek asus rendah.

Berdasarkan data di atas dapat disimpulkan bahwa laptop merek asus memilkiki keptusan pembelian yang rendah.. Keputusan pembelian dapat dipengaruri oleh Diferensiasi, Promosi dan Positioning..

Berdasarkan literatur tersebut penulis tertarik melakukan penelitian dengan judul "Pengaruh Diferensiasi, Promosi dan Positioning terhadap Keputusan Pembelian Laptop Merek Asus".

\section{LANDASAN TEORI}

\section{Keputusan Pembelian}

Menurut Sangadji (2013:123) Pengambilan keputusan konsumen adalah proses pemecahan masalah yang di arahkan pada sasaran. Pemecahan masalah konsumen sebenarnya merupakan suatu aliran tindakan timbal balik yang berkesinambungan di antara faktor-faktor lingkungan, proses kognitif dan efektif, serta tindakan perilaku.

Periset dapat membagi aliran ini ke dalam beberapa tahap dan subproses yang berbeda untuk menyederhanakan masalah (problem solving) genetik yang menjelaskan lima tahapan atau proses dasar. 
Tahap Pengambilan Keputusan Pada Konsumen Ali Hasan (2013:180):

1. Pengenalan masalah

Masalah merupakan hasil dari perbedaan antara keadaan yang diinginkan konsumen dan keadaan yang sebenarnya dihadapi, dan konsumen termotivasi untuk mengatasi perbedaan tersebut dan karena itu mereka memulai proses pembelian.

2. Pencarian informasi

Setelah konsumen mengakui bahwa mereka merasakan adanya masalah, mereka mencari informasi tentang produk dan layanan yang dapat memecahkan masalah itu.

3. Evaluasi alternatif

Pada tahap ini konsumen membandingkan merek dan produk yang dipertimbangkan mereka. Bagaimana marketer meningkatkan kemungkinan bahwa tawaran merek bagian dari yang dipertimbangkan konsumen? Konsumen mengevaluasi manfaan fungsional dan psikologis dari tawaran itu. Tidak ada proses evaluasi tunggal dan sederhana yang digunakan oleh semua konsumen atau bahkan oleh seorang konsumen dalam semua situasi pembelian.

4. Keputusan pembelian

Dalam tahap evaluasi, konsumen membentuk preverensi diantara merek-merek dalam kelompok pilihan. Konsumen mungkin juga membentuk minat pembelian untuk membeli merek yang paling disukai.

5. Perilaku setelah pembelian

Setelah membeli produk, konsumen akan merasakan tingkat kepuasan atau ketidakpuasan tertentu. Konsumen juga akan melakuakn tindakan purnabeli dan menggunakan produk tersebut, pemasar harus benar-benar memperhatikan kedua aspek ini. Tugas pemasar tidak berakhir saat produk dibeli, tetapi terus berlanjud sampai periode purnabeli.

\section{Faktor yang mempengaruhi Perilaku Pembelian}

Menurut Abdullah (2012:202) Faktor-faktor utama yang mempengaruhi prilaku pembelian adalah

1. Faktor Budaya

Faktor budaya mempunyai pengaruh yang paling luas dan mendalam terhadap prilaku konsumen.
a. Kultur
b. Sub Kultur
c. Kelas Sosial

2. Faktor Sosial

Prilaku seorang konsumen juga dipengaruhi oleh faktor-faktor sosial seperti kelompok acuan, keluarga serta peran dan status sosial.
a. Kelompok Acuan
b. Keluarga
c. Peran dan Status

3. Faktor Pribadi

Keputusan seorang pembeli juga dipengaruhi oleh karakteristik pribadi, yaitu usia pembeli dan tahap siklus hidup, pekerja, kondisi ekonomi, gaya hidup, serta kepribadian dan konsep diri pembeli.

4. Faktor Psikologis

Pilihan pembelian seseorang dipengaruhi pula oleh empat faktor psikologi utama, motivasi, persepsi, pengetahuan, serta keyakinan dan sikap.

\section{Strategi Pemasaran}


Menurut Sofjan Assauri (2014:168) Strategi pemasaran pada dasarnya adalah rencana yang menyeluruh, terpadu dan menyatu di bidang pemasaran, yang memberikan panduan tentang kegiatan yang akan dijalankan untuk dapat tercapainya tujuan pemasaran suaru perusahaan. Dengan kata lain, strategi pemasaran adalah serangkaian tujuan dan sasaran, kebijakan dan aturan yang memberi arah kepada usahausaha pemasaran perusahaan dari waktu ke waktu, pada masing-masing tingkatan dan acuan serta alokasinya.

\section{Strategi Diferensiasi}

Diferensiasi produk adalah kegiatan memodifikasi produk menjadi menarik. Diferensiasi ini memerlukan penelitian pasar yang cukup serius agar bisa benar-benar berbeda, diperlukan pengetahuan tentang produk desain. Diferensiasi produk ini bisanya hanya mengubah sedikit karakter produk, antara lain kemasan dan tema promosi tanpa mengubah spesifikasi fisik produk meskipun itu diperlukan. Tujuan diferensiasi produk merupakan elemen dimana pelaku pasar berusaha membedakan produk mereka dengan produk pesaing suatu bentuk persaingan bukan harga. Adapun indikator dari diferensiasi ini adalah :

1. Ciri Khas

2. Nilai

3. Citra

\section{Hubungan antara Diferensiasi Terhadap Keputusan Pembelian}

Strategi diferensiasi yang dilakukan oleh perusahaan atas produknya mendorong terciptanya keunggulan dalam bersaing. Dengan penerapan diferensiasi yang baik dan unggul, maka perusahaan akan dapat memenangkan persaingan yang ada, karena konsumen akan lebih memilih untuk membeli dan menggunakan suatu produk dari perusahaan yang kebih unggul.

Berdasarkan penjelasan tersebut, penulis dapat menyimpulkan bahwa diferensiasi adalah upaya yang dilakukan perusahaan untuk membedakan produk yang ditawarkan dengan pesaing yang dapat menciptakan pembeda dan memiliki nilai tambah bagi perusahaan dan berpengaruh terhadap keputusan pembelian.

\section{Promosi}

Menurut Buchari Alma (2011:179) promosi adalah sejenis komunikasi yang memberi penjelasan yang meyakinkan calon konsumen tentang barang dan jasa. Tujuan promosi adalah memperoleh perhatian, mendidik, mengingatkan, dan meyakinkan calon konsumen. Suatu kegiatan promosi jika dilaksanakan dengan baik dapat mempengaruhi konsumen mengenai dimana dan bagaimana konsumen membelanjakan pendapatannya.

Ada enam strategi pokok dalam strategi promosi yaitu :

1) Strategi pengeluaran promosi

2) Strategi bauran promosi

3) Strategi pemilihan media

4) Strategi copy periklanan

5) Strategi penjualan

6) Strategi motivasi dan penyeliaan tenaga penjual

\section{Hubungan Antara Promosi Terhadap Keputusan Pembelian}

Kegiatan promosi dapat dikatakan sebagai penentu keberhasilan kegiatan pemasaran, karena dalam kegiatan promosi ini perusahaan harus mampu mengkomunikasikan dengan baik semua keunggulankeunggulan yang dimilikinya. Apabila konsumen tidak dapat memahami dan mengerti keunggulan apa yang dimiliki oleh produk suatu perusahaan maka konsumen tidak akan membeli produk tersebut.

Tetapi sebaliknya jika perusahaan mengkomunikasikan dengan baik dan konsumen mampu memahaminya dengan baik maka dapat menimbulakan ketertarikan konsumen terhadap produk dan terdorong untuk membeli dan menggunakannya.

Adapun indikator dari promosi adalah : 
1. Periklanan

2. Promosi Penjualan

3. Pemasaran Langsung

4. Hubungan Masyarakat

\section{Strategi Penempatan Posisi (Positioning)}

Menurut Budi (2013:94) Positioning merupakan konsep psikologis yang terkait dengan bagaimana konsumen yang ada ataupun calon konsumen dapat menerima perusahaan tersebut dan produknya dibandingkan dengan produk lain. Latar belakang pemikirian positioning ini adalah untuk menciptakan citra (image) yang diharapkan, maksudnya adalah langsung terkait dengan bagaimana konsumen yang berada di segmen pasar tertenutu atau spesifik itu mempersepsikan jasa perusahaan.

Tugas yang dilakukan dalam memposisikan suatu produk terdiri dari tiga langkah yaitu :

1. Mengidentifikasi keunggulan bersaing yang mungkin untuk membangun posisi

2. Memilih keunggulan bersaing yang tepat

3. Mengkomunikasikan dan menyampaikan posisi yang dipilih kepada pasar secara efektif

Menurut Ali Hasan (2013: 396) tujuan positioning adalah :

1. Untuk menempatkan atau memposisikan produk di pasar sehingga produk tersebut terpisah atau berbeda dengan merek-merek yang bersaing

2. Untuk memposisikan produk sehingga dapat menyampaikan beberapa hal pokok kepada para pelanggan

3. Untuk mencapai hasil yang diharapkan

\section{Hubungan Antara Positioning Terhadap Keputusan Pembelian}

Strategi positioning yang dilakukan suatu perusahaan dengan baik dapat menciptakan citra produk yang baik dalam benak konsumen. Hal tersebut pada akhirnya akan mempu mendorong seorang komsumen memutuskan utnuk membeli dan menggunakan produk perusahaan tersebut. Dengan demikian maka dapat meningkatkan keputusan pembelian.

Berdasarkan pendapat para ahli tersebut maka penulis dapat menyimpulkan bahwa positioning adalah tindakan yang dilakukan perusahaan untuk mendapatkan celah dibenak konsumen agar memiliki persepsi dan citra yang khusus terhadap produk dan perusahaan. Strategi positioning yang dilakukan suatu perusahaan dengan baik dapatmenciptakan citra produk yang baik dalam benak konsumen. Hal tersebut pada akhirnya akan mampu mendorong seorang konsumen memutuskan untuk membelidan menggunakan produk perusahaan tersebut. Dengan demikian maka dapat meningkatkan volume pembelian produk perusahaan.

\section{Kerangka Fikir}




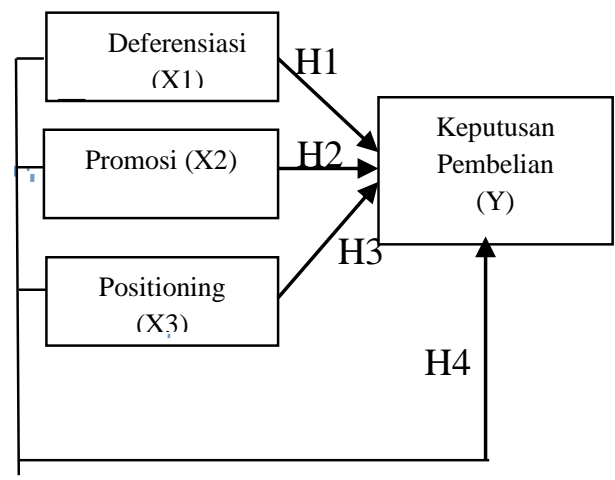

\section{Gambar 1.1 Variabel Dependen (Y)}

\section{Hipotesa}

1. Differensiasi berpengaruh secara parsial terhadap keputusan pembelian laptop merek Asus pada mahasiswa fakultas ekonomi UPI "YPTK" Padang.

2. Promosi berpengaruh secara parsial terhadap keputusan pembelian laptop merek Asus pada mahasiswa fakultas ekonomi UPI "YPTK" Padang.

3. Positioning berpengaruh secara parsial terhadap keputusan pembelian laptop merek Asus pada mahasiswa fakultas ekonomi UPI "YPTK" Padang.

4. Diferensiasi, promosi dan positioning secara bersama-sama terhadap keputusan pembelian laptop merek Asus pada mahasiswa fakultas ekonomi UPI "YPTK" Padang.

\section{METODE PENELITIAN}

\section{Analisis Regresi berganda}

Analisis ini untuk meramalkan bagaimana keadaan (naik turunnya) variabel dependen (kriterium), bila dua atau lebih variabel independen sebagai faktor prediktor dimanipulasi (dinaik turunkan nilainya. Rumus Sugiono (2014:192) :

$$
Y=a+b_{1} X_{1}+b_{2} X_{2}+b_{3} X_{3+e}
$$

Keterangan :

$\mathrm{Y}=$ Keputusan Pembelian

$\mathrm{X}_{1} \quad=$ Deferensiasi

$\mathrm{X}_{2} \quad=$ Promosi

$\mathrm{X}_{3} \quad=$ Positioning

a $\quad=$ Konstanta

$b_{1}, b_{2}, b_{3}=$ Koefisien regresi masing-masing variabel

\section{Uji Hipotesis}

Interval estimasi yang kita kembangkan sebelumnya merupakan satu teknik didalam statistic untuk membuat kesimpulan (inference)tentang sifat populasiberdasarkan data sampel. Metode statistic lain yang juga bisa digunakan untuk membuat kesimpulan sifat populasi dari data sampel adalah uji populasi. Uji hipotesis adalah pengujian yang bertujuan untuk mengetahui apakah kesimpulan pada sampel dapat berlaku untuk populasi Priyatno (2012:11).

\section{Pengujian Secara Parsial (Uji-t)}

Uji-t dilakukan untuk mengetahui tingkat signifikan pengaruh variabel bebas terhadap variabel terikat secara parsial, dengan langkah-langkah sebagai berikut : 
1. Menentukan rumusan hipotesis :

a) Ho: $b_{1}=0$, berarti diferensiasi, promosi dan positioning secara parsial tidak mempunyai pengaruh yang signifikan terhadap keputusan pembelian.

b) Ha: $b_{1} \neq 0$, berarti diferensiasi, promosi dan positioning secara parsial mempunyai pengaruh yang signifikan terhadap keputusan pembelian.

2. Menentukan nilai $t_{\text {tabel, }}$, pada derajat kebebasan $(\mathrm{d}, \mathrm{f})=\mathrm{n}-\mathrm{k}-1$, dengan $\alpha=5 \%$

3. Membandingkan $t_{\text {hitung }}$ dengan $t_{\text {tabel }}$.

4. Mengambil keputusan :

a) Bila $t_{\text {hitung }}<t_{\text {tabel }}$, maka Ho diterima sedangkan Ha ditolak, artinya menunjukkan, diferensiasi, promosi, dan potioning secara parsial tidak mempunyai pengaruh yang signifikan terhadap keputusan pembelian.

b) Bila $t_{\text {hitung }}>t_{\text {tabel, }}$ maka Ha diterima sedangkan Ho ditolak, artinya deferensiasi, promosi, dan positioning secara parsial mempunyai pengaruh yang signifikan terhadap keputusan pembelian.

Rumus Priyatno (2012:84) :

$$
\text { thitung }=\frac{\mathrm{r} \sqrt{\mathrm{n}-\mathrm{k}-1}}{\sqrt{1-r^{2}}}
$$

Keterangan :

$\mathrm{r} \quad=$ koefisien korelasi parsial

$\mathrm{k} \quad=$ jumlah variabel independen

$\mathrm{n} \quad$ = jumlah data (kasus)

\section{Pengujian Secara Simultan (Uji-F)}

Uji-F dilakukan untuk mengetahui tingkat signifikansi pengaruh variabel bebas terhadap variabel terikat secara bersama-sama, dengan langkah-langkah sebagai berikut :

1. Menentukan rumusan hipotesis :

a) Ho : $b_{1}=b_{2}=b_{3}=b_{4}=0$, berarti deferensiasi, promosi dan positioning secara bersama-sama tidak mempunyai pengaruh yang signifikan terhadap keputusan pembelian.

b) $\mathrm{Ha}: \mathrm{b}_{1} \neq \mathrm{b}_{2} \neq \mathrm{b}_{3} \neq \mathrm{b}_{4} \neq 0$, berarti diferensiasi, promosi dan positioning secara bersama-sama mempunyai pengaruh yang signifikan terhadap keputusan pembelian.

2. Menentukan nilai $F_{\text {hitung }}$ pada $\alpha$ atau tingkat signifikansi $=5 \%$, dan derajat kebebasan $(\mathrm{d}, \mathrm{f}) \mathrm{df} 1=\mathrm{k}$ dan df $2=n-k-1$

3. Menentukan besarnya $F_{\text {hitung }}$

4. Mengambil keputusan :

a) Bila $F_{\text {hitung }}<F_{\text {tabel }}$, maka Ho diterima berarti Ha ditolak. Artinya diferensiasi, promosi dan positioning secara bersama-sama tidak mempunyai pengaruh yang signifikan terhadap keputusan pembelian.

b) Bila $F_{\text {hitung }}>F_{\text {tabel}}$, maka Ho ditolak berarti Ha Diterima. Artinya deferensiasi, promosi dan positioning secara bersama-samamempunyai pengaruh yang signifikan terhadap keputusan pembelian.

Rumus Priyatno (2012:80) :

$$
\text { fhitung }=\frac{\mathrm{R}^{2} / \mathrm{k}}{\left(1-R^{2}\right) /(n-k-1)}
$$

Keterangan :

$\mathrm{R}^{2} \quad=$ koefisien determinasi 
$\mathrm{n} \quad=$ jumlah data (kasus)

$\mathrm{k} \quad=$ jumlah variabel independen

\section{HASIL DAN PEMBAHASAN}

\section{Uji Hipotesis}

Dari hasil penelitian, dapat dilihat tabel sebagai berikut :

Tabel 1.2

Pengujian Secara Parsial Atas Semua Variabel Independen

\section{Sumber :SPSS 21.0 dan data primer yang diolah}

\begin{tabular}{|c|c|c|c|c|}
\hline No & $\begin{array}{c}\text { Variabel } \\
\text { Independen }\end{array}$ & $\mathrm{t}_{\text {hitung }}$ & $\mathrm{t}_{\text {abel }}$ & Sig. \\
\hline 1 & Diferensiasi & 2,355 & 1,985 & .021 \\
\hline 2 & Promosi & 9,492 & 1,985 & .000 \\
\hline 3 & Positioning & 0,573 & 1,985 & .568 \\
\hline
\end{tabular}

\section{Pengaruh Variabel Diferensiasi terhadap keputusan pembelian}

Dari tabel diatas diketahi $t$ hitung $>t$ tabel $(2,355>1,985)$ dengan tingkat signifikan $(0,021<$ $0,05)$, artinya secara parsial ada pengaruh yang signifikan antara diferensiasi dengan keputusan pembelian. Dengan demikian Ho ditolak Ha diterima.

\section{Pengaruh Variabel Promosi terhadap keputusan pembelian}

Dari tabel diatas diketahi $t$ hitung $>\mathrm{t}$ tabel $(9,492>1,985)$ dengan tingkat signifikan $(0,000<$ $0,05)$, artinya secara parsial ada pengaruh yang signifikan antara promosi dengan keputusan pembelian. Dengan demikian Ho ditolak Ha diterima.

\section{Pengaruh Variabel Positioning terhadap keputusan pembelian}

Dari tabel diatas diketahi $t$ hitung $>\mathrm{t}$ tabel $(0,573>1,985)$ dengan tingkat signifikan $(0,567<0,05)$, artinya secara parsial tidak ada pengaruh yang signifikan antara positioning dengan keputusan pembelian. Dengan demikian Ho diterima Ha ditolak.

\section{KESIMPULAN}

Dari hasil penelitian yang telah penulis lakukan tentang "Pengaruh Diferensiasi, Promosi dan Positioning Terhadap Keputusan Pembelian Laptop Merek Asus (Studi Kasus Mahasiswa Fakultas Ekonomi Universitas Putra Indonesia "YPTK" Padang ". Maka dapat di tarik beberapa kesimpulan sebagai berikut:

1. Hasil persamaan regresi $\mathbf{Y}=\mathbf{1 9 , 5 2 0}+\mathbf{0 , 1 4 9} \mathbf{X}_{\mathbf{1}}+\mathbf{0 , 4 0 5} \mathbf{X}_{\mathbf{2}}+\mathbf{0 , 0 3 2} \mathbf{X}_{\mathbf{3}}+$ e,maka dapat disimpulkan bahwa Diferensiasi memiliki pengaruh sebesar 0,149 terhadap keputusan pembelian. Maka diferensiasi memiliki pengaruh yang positif dan signifikan, dengan Ho ditolak dan Ha diterima.

2. Promosi memiliki pengaruh sebesar 0,405 terhadap keputusan pembelian. Maka promosi memiliki pengaruh yang positif dan signifikan, dengan Ho ditolak dan Ha diterima.

3. Positioning memiliki pengaruh sebesar 0,032 terhadap keputusan pembelian. Maka positioning memiliki pengaruh yang positif dan signifikan, dengan Ho ditolak dan Ha diterima.

4. Diferensiasi, promosi dan positioning memiliki pengaruh sebesar 19,520 terhadap keputusan pembelian. Maka secara bersama-sama Diferensiasi, promosi dan psitioning memiliki hubungan yang positif dan signifikan, dengan demikian Ho ditolak dan Ha diterima.

5. Dari hasilanalisis determinasi sebesar 51,5 \% hal ini menunjukkan bahwa presentase variabel indenpenden penilaian diferensiasi, promosi dan positioning terhadap keputusan pembelian. 
Sedangkan sisanya 48,5\% dipengaruhi oleh variabel lain diluar penelitian ini. Maka secara bersamasama antara penilaian diferensiasi, promosi dan positioning mempunyai pengaruh yang signifikan terhadap keputusan pembelian

6. Hasil analisis korelasi sebagai berikut:

a. Diferensiasi dengan keputusan pembelian memiliki hubungan yang lemah yaitu sebesar 0,223 dengan tingkat signifikan 0,025 .

b. Promosi dengan keputusan pembelian memiliki hubungan yang kuat yaitu sebesar0,693 dengan tingkat signifikan 0,000 .

c. Positioning dengan keputusan pembelian memiliki hubungan yang sedang yaitu sebesar 0,148 dengan tingkat signifikan 0,142 .

\section{DAFTAR PUSTAKA}

Abdullah, Thamrin dan Francis tantri. 2012. Manajemen Pemasaran. Jakarta: PT Rajagrafindo Persada.

Ali, Hasan . 2013. Marketing dan Kasus Kasus Pilihan. Yogyakarta. CAPS (Center For Academic Publishing Service).

Alma, Buchari. 2011. Manajemen Pemasaran dan Pemasaran Jasa.Bandung: Alfabeta.

Assauri, Sofjan. 2014. Manajemen Pemasaran.Jakarta: PT Rajagrafindo Persada.

Budi, Agung Permana. 2013. Manajemen Marketing Perhotelan. Yogyakarta: Andi.

Hasan, Ali. 2013. Marketing dan Kasus-Kasus Pilihan. Yogyakarta: CAPS

Center For Academic Publishing.

Julcandra. 2013. Pengaruh Diferensiasi, Promosi dan Positioning Terhadap Keputusan Pembelian Pada Laptop Dell. UPI YPTK. Padang..

Kotler, Philip dan Kevin Lane Keller. 2013. Manajemen Pemasara. Edisi Ketiga Belas, Jilid 1. Jakarta: Erlangga.

Mustain, Hasma Laely. 2012. Analisis Pengaruh Strategi Positioning Terhadap Keputusan Pembelian Pada Konsumen Starbucks Coffe Di Makasar. Universitas Hasanuddin. Makassar.

Ong, Ian Antonius dan Sugiono Sugiharto. 2013. Analisis Pengaruh Strategi Diferensiasi, Citra Merek, Kualitas Produk dan Harga Terhadap Keputusan Pembelian di Cincau Station Surabaya. Universitas Kristen Petra. Surabaya.

Peter, J.Paul dan Jerry C.Olson. 2013. Prilaku Konsumen dan Strategi Pemasaran. Jakarta: Salemba Empat.

Prasetya, Frendy. 2011. Analisis Pengaruh Diferensiasi, Promosi dan

Positioning Terhadap Keputusan Pembelian. Universitas Pendidikan Ganesha Singaraja.

Priyatno, Dwi. 2012. SPSS (Statistical Product And Service Solution Untuk Aanalisis Data \& Uji Statistic). Yogyakarta: Mediakom.

Sahetapy, Jeofer Pratama. 2013. Diferensiasi Produk, Strategi Merek, Pengaruhnya Terhadao Keputusan Pembelian Meubel UD Sinar Sakti Manado. Universitas Sam Ratulangi. Manado.

Sangadji, Etta Mamang dan Sopiah. 2013. Prilaku Konsumen. Yogyakarta: Andi.

Sugiyono. 2014. Metode Penelitian Kuantitatif,kualitatif dan R\&D. Bandung: Alfabeta.

Tjiptono, Fandy. 2011. Strategi Pemasaran. Jakarta: Andi

Tjiptono, Fandy dkk. 2012. Strategi Strategik. Yogyakarta: Andi 